\title{
COINCIDENCE OF MALIGNANCY AND CONGENITAL THROMBOPHILIA AS THE CAUSE OF DEEP VENOUS THROMBOSIS - CASE REPORT AND REVIEW OF THE LITERATURE
}

\author{
Stanciakova L, Stasko J, Jedinakova Z, Sokol J, Plamenova I, Lisa L, \\ Fedor M, jr, Kubisz P.
}

National Centre of Haemostasis and Thrombosis, Clinic of Haematology and Transfusiology, Jessenius Faculty of Medicine in Martin, Comenius University in Bratislava and University Hospital in Martin, Slovak Republic

\section{A b s t r a t}

Introduction: Deep venous thrombosis (DVT, phlebothrombosis) is a very important clinical problem with its resultant fatal pulmonary embolism (PE) as one of the possible consequences. Factor V Leiden (FV Leiden) is a genetic disorder characterized by a poor anticoagulant response to activated protein C (APC) and an increased risk of venous thromboembolism (VTE). Homozygous carriers of the FV Leiden mutation are estimated to have an 80 -fold increased lifetime relative risk of VTE. Most homozygous carriers present with VTE before 40 years of age, but some can live thrombosis-free until the sixth or seventh decade of life or even remain asymptomatic for life. Case-controlled studies of patients with cancer revealed a four-fold increase in thromboembolic occurrence in acute leukaemia, with the risk of thrombosis persisting even after remission of the disease.

Case Report: The authors present a case report of the 61-year-old patient with leukaemic transformation of myelodysplastic syndrome (MDS) to acute myeloid leukaemia (AML) and development of DVT of the left leg (LL) as the first clinical manifestation of homozygous FV Leiden carrier. Due to his diagnosis it was not possible to indicate surgical treatment of DVT. After initial treatment with subcutaneous low molecular weight heparin (LMWH) and continuous intravenous application of unfractionated heparin (UFH) the deficiency of antithrombin III (AT III) potentiating the persistence of his hypercoagulable state developed. Treatment with the new oral anticoagulant rivaroxaban, vasoprotective and antithrombotic drugs in the combination with mechanical methods of VTE prophylaxis led to a reduction in edema of left thigh and calf by $3.5 \mathrm{~cm}$ and $4 \mathrm{~cm}$, respectively. Son of the patient experienced DVT at the age of 27 years, too.

Conclusion: In this report, we describe a case of the patient with DVT during the leukaemic transformation of MDS to AML as a relatively late first clinical manifestation of homozygous FV Leiden mutation. At the same time the article deals with the clinical aspects of discussed thrombophilia in the relatives of the patient, as well as with the etiopathogenesis, pharmacologic treatment options and possible complications of DVT (PE, pulmonary hypertension and post-thrombotic syndrome).

Keywords: deep venous thrombosis, venous thromboembolism, factor V Leiden, acute myeloid leukaemia

\section{INTRODUCTION}

Deep venous thrombosis (DVT, phlebothrombosis) is a very important clinical problem with its resultant fatal pulmonary embolism (PE) as one of the possible consequences. There is an increasing tendency to consider DVT and PE as two different manifestations of venous thromboembolism (VTE) (1).

Factor V Leiden (FV Leiden) is a genetic disorder characterized by a poor anticoagulant response to activated protein C (APC) and an increased risk of VTE (2). Homozygous carriers of the FV Leiden mutation are estimated to have an 80 -fold increased lifetime relative risk of VTE $(3,4)$.

The first description of DVT in patients with cancer was made by Bouillard in 1823 although this was popularly first credited to Armand Troussean, the French Physician, in

Corresponding a u thor:

Lucia Stanciakova, MD, National Centre of Haemostasis and Thrombosis, Clinic of Haematology and Transfusiology, University Hospital, Kollarova Str. N. 2, 03659 Martin, Slovak Republic

Phone/fax: +421 43 4203842; e-mail: Lucia.Stanciakova@jfmed.uniba.sk 
1865 (5). Case-controlled studies of patients with cancer revealed a four-fold increase in thromboembolic occurrence in acute leukaemia, with the risk of thrombosis persisting even after remission of the disease (6).

Patients with DVT may experience increased tension in an extremity. Swelling becomes clinically significant when the difference in thigh circumference is more than $2 \mathrm{~cm}$ and from 1.5 to $2 \mathrm{~cm}$ in calf circuit when compared with the other extremity. The skin is usually warm and red. Pratt's sign and Homans sign (calf pain at dorsiflexion of the foot) may also be positive (7). Phlegmasia dolens is a rare disorder caused by massive venous thrombosis. The clinical condition is subclassified as phlegmasia cerulea dolens (PCD) and phlegmasia alba dolens (PAD). In PCD, the mortality rate is high, and amputation for venous gangrene is needed. PAD is a mild form of PCD; the collateral venous system is intact, and the prognosis is better than for PCD (8).

In this report, we describe a case of the patient with DVT during the leukaemic transformation of MDS to AML as a relatively late first clinical manifestation of homozygous FV Leiden mutation. At the same time the article deals with the clinical aspects of discussed thrombophilia in the relatives of the patient, as well as with the etiopathogenesis, pharmacologic treatment options and possible complications of DVT (PE, pulmonary hypertension and post-thrombotic syndrome). We also provide an example of successful treatment of DVT with new oral anticoagulant - rivaroxaban.

\section{CASE REPORT}

61-year-old patient, who has not been treated for any disease except minor conservative interventions, was admitted to the Clinic of Haematology and Transfusiology, University Hospital in Martin for the treatment of the underlying disease - leukaemic transformation of myelodysplastic syndrome-refractory anaemia with excess of blasts type 2 (MDS-RAEB2) to acute myeloid leukaemia type MO/M1 (AML M0/M1).

During his second hospitalization, in the morning of 14 February 2014 the patient suddenly experienced symptoms of DVT of the left leg (LL). Compressive and drilling pain of LL highlighted in the popliteal fossa with a maximum intensity during the first three days occured. Pain alleviated gradually over the next one and a half weeks. He felt tension and slightly increased temperature of the extremity with no change in its colour. The patient hardly passed few meters and because of the swelling he could not bend the knee. Swelling of the calf and thigh extended into the left inguinal level with an increase in the circumference of thigh and calf of LL by approximately $10 \mathrm{~cm}$ when compared with the contralateral side (see Figure 1).

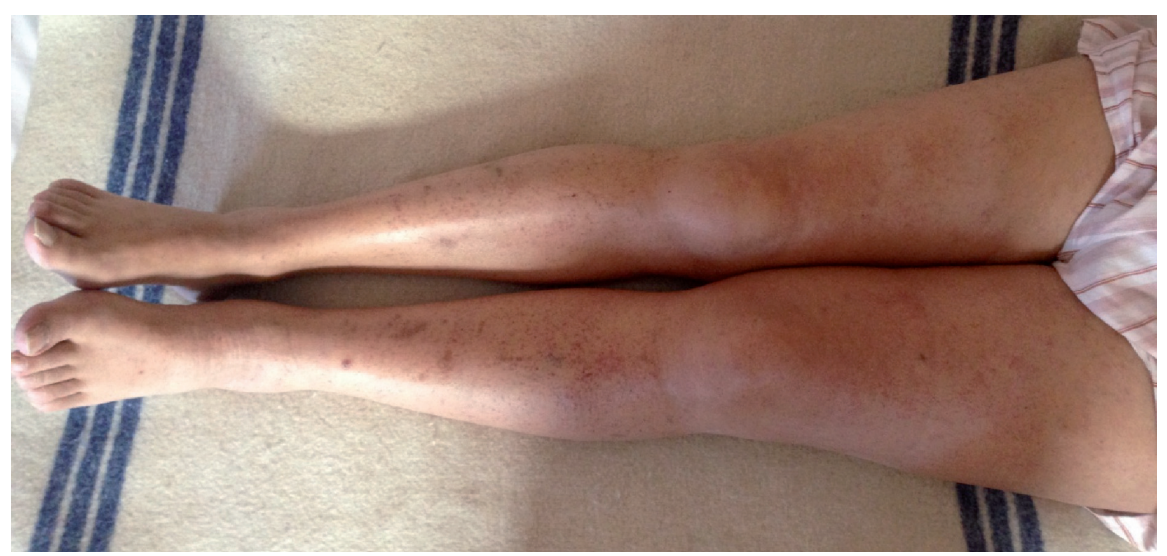

Fig. 1 Left leg of the patient (March 5, 2014) 
The initial ultrasonography of the deep venous system of the LL realized on 14 February 2014 confirmed partial thrombosis of femoral vein distal to the connection with saphena magna vein with a residual flow in the periphery of the vascular lumen, complete thrombosis of superficial femoral vein continuing distal to popliteal vein and veins of the calf (see Figure 2).
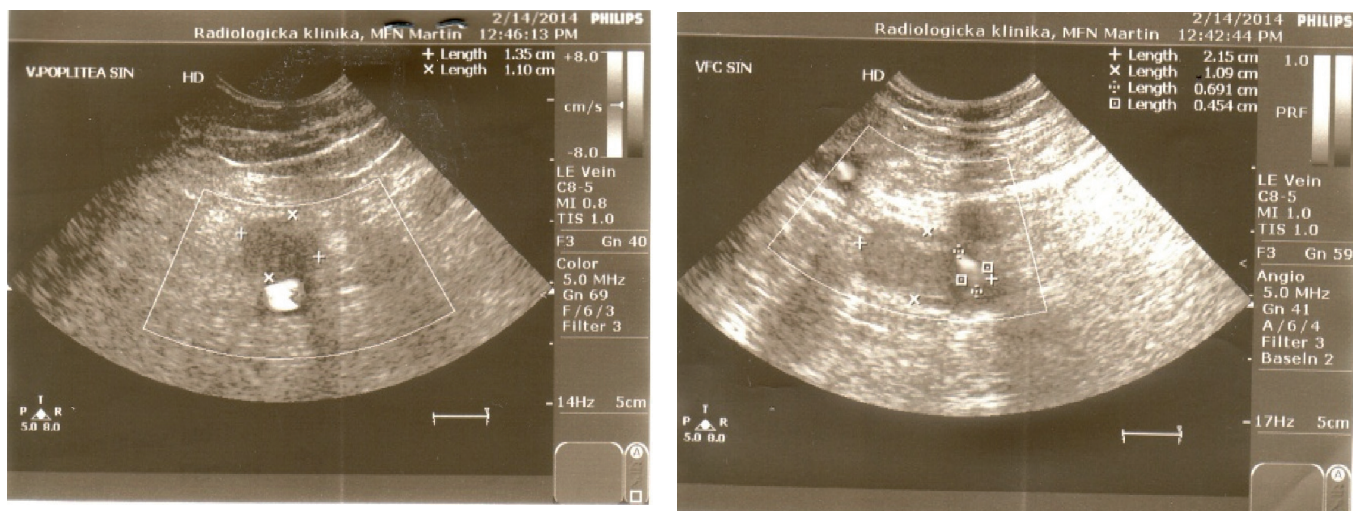

Fig. 2 Ultrasonography of the deep venous system of the left leg (February 14, 2014).

Quantitative D-dimer assay confirmed increased levels of D-dimers (4.680 mg/l). The analysis of deoxyribonucleic acid (DNA analysis) of blood samples revealed the presence of a homozygous FV Leiden mutation (genotype AA when labelling as G1691A) and homozygous MTHFR A1298C mutation (genotype CC) leading to mild hyperhomocysteinemia (19.61 $\mu \mathrm{mol} / \mathrm{l})$. Patient did not smoke at the time of development of DVT, but in the past he did.

Due to his diagnosis it was not possible to indicate surgical treatment of DVT. Based on these findings, the anticoagulant therapy with subcutaneous low molecular weight heparin (LMWH, Fraxiparine ${ }^{\circledR}$ ) and continuous intravenous application of unfractionated heparin (UFH) was indicated. Development of changes of activated partial thromboplastin time (APTT) and antithrombin III (AT III) in the course of use of UFH and LMWH is illustrated in Figure 3.

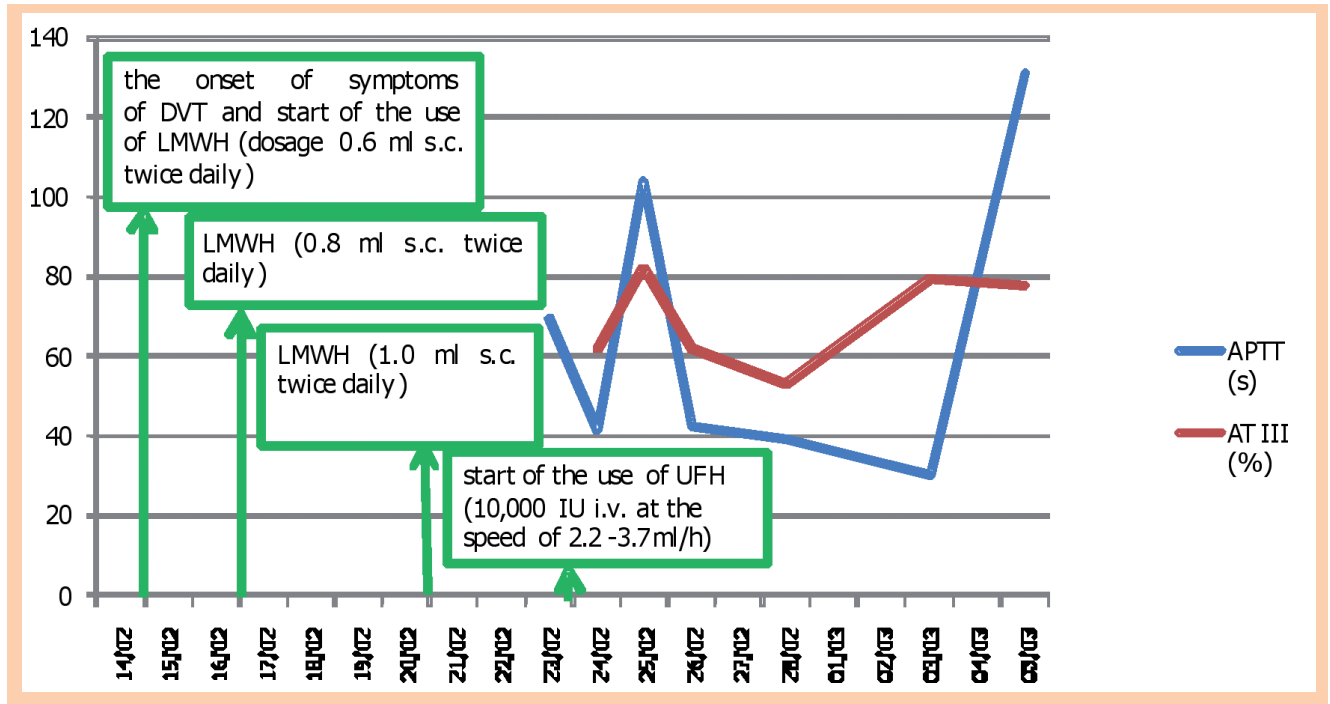

Fig. 3 Development of changes of APTT and AT III in the course of the use of UFH and LMWH Abbreviations: APTT - activated partial thromboplastin time, AT III - antithrombin III, DVT - deep venous thrombosis, IU - international unit, i.v. - intravenously, LMWH - low molecular weight heparin, s.c. - subcutaneously, UFH - unfractionated heparin 
During heparin therapy, there was a regression of edema of the left thigh and calf by $4.5 \mathrm{~cm}$. However, as a result of long-term heparin therapy, the patient developed deficiency of AT III, so its substitution was inevitable.

Rivaroxaban (Xarelto ${ }^{\circledR}$ ) is an oral, direct, competitive, quick and dose-dependent inhibitor of coagulation factor Xa (FXa) $(9,10)$. From 6 to 23 March the dosage $10 \mathrm{mg}$ in the morning and $20 \mathrm{mg}$ in the evening of rivaroxaban was indicated. Subsequently the patient developed thrombocytopenia, so reduced dose of the drug (20 mg in the evening) was approved. Since the beginning of the treatment with rivaroxaban the circumference of thigh decreased by $3.5 \mathrm{~cm}$ and calf by $4 \mathrm{~cm}$. Regression of edema of thigh and calf of LL during the use of heparin therapy is documented in Table 1 .

Tab. 1. Regression of edema of thigh and calf of LL during the use of heparin therapy and its comparison with the circumference of RL

\begin{tabular}{|c|c|c|c|c|c|}
\hline Date & Circumference of thigh & Difference & Circumference of calf & Difference & Note \\
\hline & of $\mathbf{L}(\mathbf{c m})$ & with RL (cm) & of $\amalg(\mathbf{c m})$ & with RL (cm) & \\
\hline $14 / 02$ & 59 & 10 & 41 & 10 & onset of DVT \\
\hline $14 / 02$ & & & & & heparin therapy \\
\hline $27 / 02$ & 56 & 7 & 38 & 7 & \\
\hline $28 / 02$ & 56 & 7 & 38 & 7 & \\
\hline $04 / 03$ & 55 & 6 & 37 & 6 & \\
\hline $06 / 03$ & & & & & Xarelto $\mathbb{R}$ \\
\hline $18 / 03$ & 54.5 & 5.5 & 36.5 & 5.5 & \\
\hline $19 / 03$ & 52 & 3 & 36 & 5 & \\
\hline $20 / 03$ & 52 & 3 & 36 & 5 & \\
\hline $21 / 03$ & 51.5 & 2.5 & 36 & 5 & \\
\hline $22 / 03$ & 51 & 2 & 35.5 & 4.5 & \\
\hline $23 / 03$ & 50 & 1 & 35 & 4 & \\
\hline $24 / 03$ & 50 & 1 & 35 & 4 & \\
\hline $25 / 03$ & 50 & 1 & 35 & 4 & \\
\hline $26 / 03$ & 50 & 1 & 35 & 4 & \\
\hline $27 / 03$ & 50 & 1 & 34.5 & 3.5 & \\
\hline $02 / 04$ & 50 & 1 & 33.5 & 2.5 & \\
\hline $15 / 04$ & 51 & 2 (lower 2/3) & 33 & 2 & \\
\hline $22 / 04$ & 51 & 2 (lower $1 / 3$ ) & 32.5 & 1.5 & \\
\hline
\end{tabular}

Abbreviations: DVT - deep venous thrombosis, LL - left leg, RL - right leg

Co-administration of vasoprotective and moderately antithrombotic acting drugs (Detralex ${ }^{\circledR}$ and Vessel Due $\mathrm{F}^{\circledR}$ ) in the combination with mechanical methods of VTE prophylaxis (compression bandages, limb positioning, sufficient exercise regimen) led to further alleviation of the symptoms of DVT of LL. Control ultrasonographic examination realized on 25 March 2014 confirmed the persistence of partial thrombosis of the external iliac vein and common iliac vein and complete thrombosis of the superficial femoral vein. After discussed complex therapy popliteal vein was recanalized marginally (partial thrombosis).

The patient stated that thrombotic complications occurred also in other members of his family. To be more exact, in his 27-year-old son thrombosis of left posterior tibial vein was diagnosed in May 2011. Genetic analysis confirmed heterozygous FV Leiden mutation (genotype GA) and ruled out the presence of the prothrombin G20210A variant. Further investigations for thrombophilia were negative. After initial administration of LMWH, warfarin anticoagulant therapy was indicated. The son smoked before thrombo- 
sis, too. Although patient s mother experienced myocardial infarction at the age of 81 years, according to the anamnestic data she had the tendency to thrombophilia. In 35year-old daughter of the patient, who is currently pregnant, screening for thrombophilia was recommended. Sister of discussed patient is healthy without thrombotic complications.

\section{DISCUSSION}

Venous thrombosis, including DVT and PE, occurs at an annual incidence of about 1 per 1000 adults (11). Risk factors for the development of thrombotic complications, except congenital and acquired (e.g. antiphospholipid syndrome) thrombophilia are advancing age, immobilization (during long-term hospitalization), obesity, trauma, major surgery and orthopedic surgery, fractures of the thigh, pelvis and hips, liver disease, chronic myeloproliferative neoplasms, other malignant and inflammatory diseases, stroke, cardiovascular disease, chronic respiratory disease or intestinal disease in the personal history, heparin-induced thrombocytopenia (HIT) and last but not least vascular catheters $(11,12,13)$. The most common factors are hospitalization $(52 \%)$, cancer $(48 \%)$ and surgery $(42 \%)(11)$. Among all the mentioned factors those contributing to relatively late development of thrombosis in our patient at the age of 61 years were mainly malignancy (leukaemic transformation of MDS-RAEB-2 to AML M0/M1), hospitalization lasting more than six weeks (period from 22 January 2014 to 7 March 2014) and inherited thrombophilia (homozygous FV Leiden mutation, homozygous 5,10-methylenetetrahydrofolate reductase (MTHFR) A1298C mutation leading to mild hyperhomocysteinemia). HIT as an additional risk factor for venous thrombosis in our patient was not developed.

As discussed earlier, initial treatment of DVT with LMWH at the therapeutic dose in our patient was started. Unfortunately, control ultrasonographic examination did not show significant change in the extension of the thrombosis, so treatment with UFH was indicated. AT III normally acts as the most powerful natural inhibitor of coagulation. It necessarily produces complexes with heparin (12). When present in blood for long periods heparin significantly reduces AT III, the proteinase inhibitor that is responsible for the anticoagulant effect of this drug (14). In the connection with heparin therapy the deficiency of AT III potentiating the persistence of procoagulant state developed in our patient, too (see Figure 4). Therefore, intensive monitoring of APTT and level of AT III using chromogenic methods with subsequent careful choice of the appropriate speed of the administration of UFH and substitution of AT III were inevitable.

Direct inhibitors of FXa exert antithrombotic effects without having to interact with AT III. Moreover, these agents can be given in fixed doses and offer a less complex therapeutic regimen for patients (9). These were preferential reasons for initiation of treatment with rivaroxaban. Last, but not least, our patient required long-term therapy and prevention of recurrence of DVT, so this drug was the ideal option - rivaroxaban could be easily administered in the outpatient setting with effect comparable to heparin therapy (decrease in the circumference of left thigh by $3.5 \mathrm{~cm}$ and left calf by $4 \mathrm{~cm}$ in the course of treatment with rivaroxaban vs. regression of edema by $4.5 \mathrm{~cm}$ during heparin therapy), thus improving his quality of life up to and including today. 


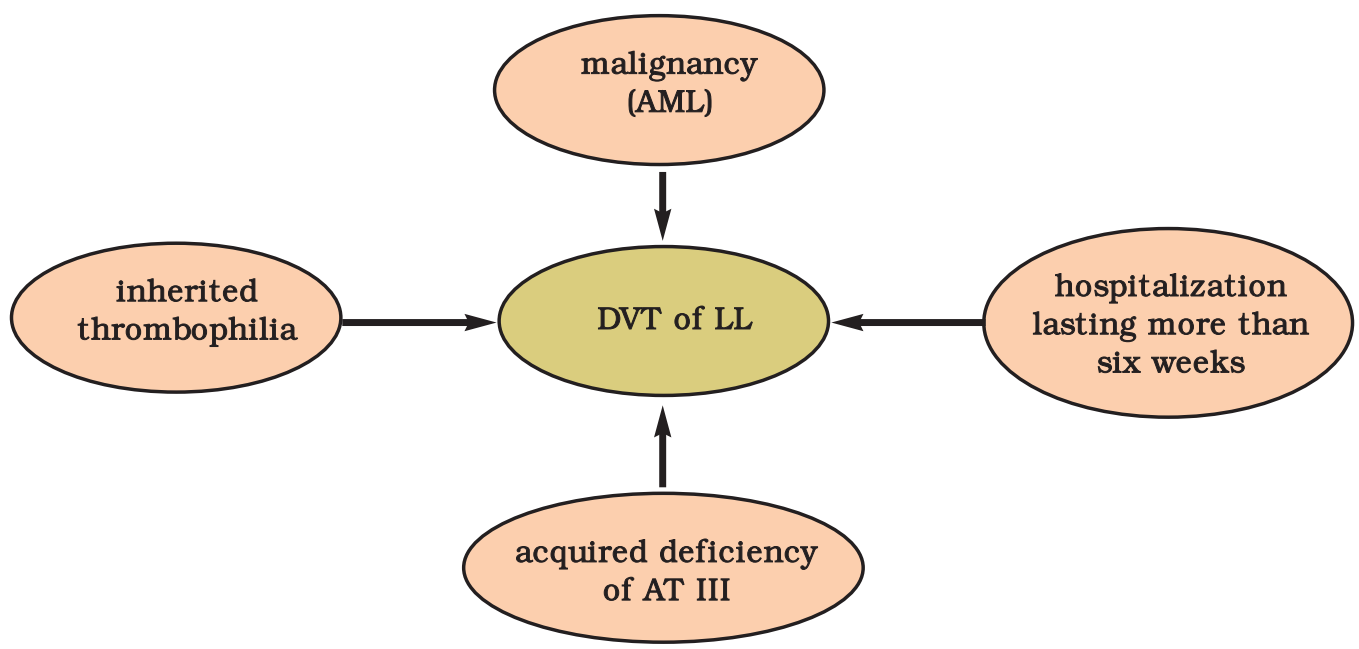

Fig. 4. Risk factors contributing to DVT of LL in the patient Abbreviations: AML - acute myeloid leukaemia, AT III - antithrombin III, DVT - deep venous thrombosis, LL - left leg

Most homozygous FV Leiden carriers present with VTE before 40 years of age, but some can live thrombosis-free until the sixth or seventh decade of life or even remain asymptomatic for life. Most cases of VTE in these patients arise as a result of other associated conditions (4). FV Leiden mutation showed a 12- to 17 -fold increase in VTE among patients with cancer, a rate likely to be similar in patients with leukaemia. The prothrombotic factors include hyperleukocytosis, increased expression of tissue factor and its activation in leukaemic cells, and the prothrombotic adverse effects of therapeutic agents and vascular access catheters (6).

The incidence of thrombosis in malignant haematologic disorders in general is as high as or even higher than in solid tumor. Process, in which tumor cell products interact with host cells (monocytes/macrophages, endothelial cells, platelets, fibroblasts, parenchymal cell, etc.) to produce the hypercoagulable state, is further complicated by the prolonged periods of therapy-induced cytopenias and the rapid induction by chemotherapy of malignant cell destruction (with elaboration of tumor products) (15). Dynamics of blood count with the exclusion of hyperleukocytosis and HIT are documented in Figure 5 and in Figure 6.

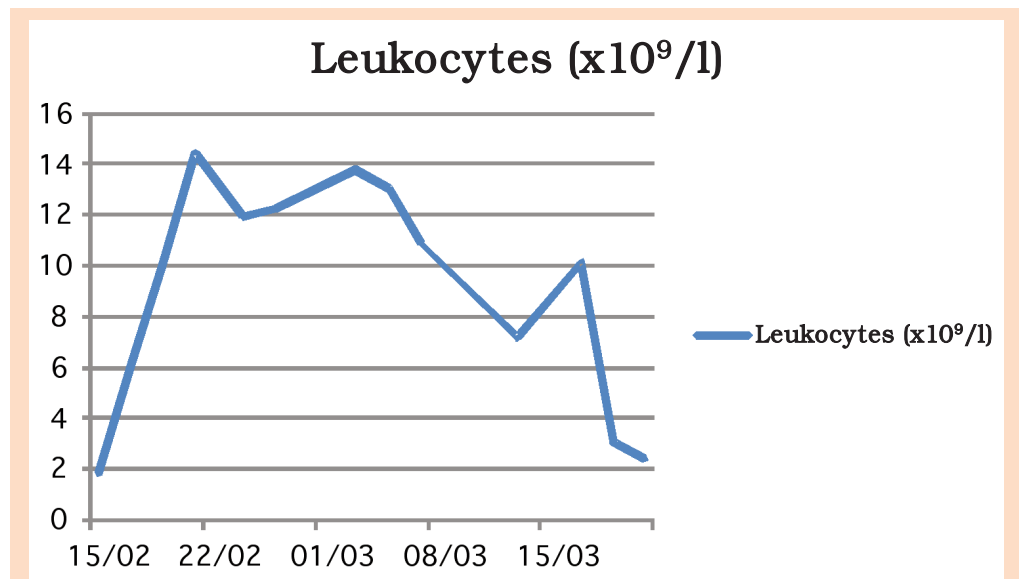

Fig. 5. Dynamics of leukocyte count during first days after development of DVT excluding hyperleukocytosis

Abbreviations: DVT - deep venous thrombosis 


\section{Platelets $\left(\times 10^{9} / 1\right)$}

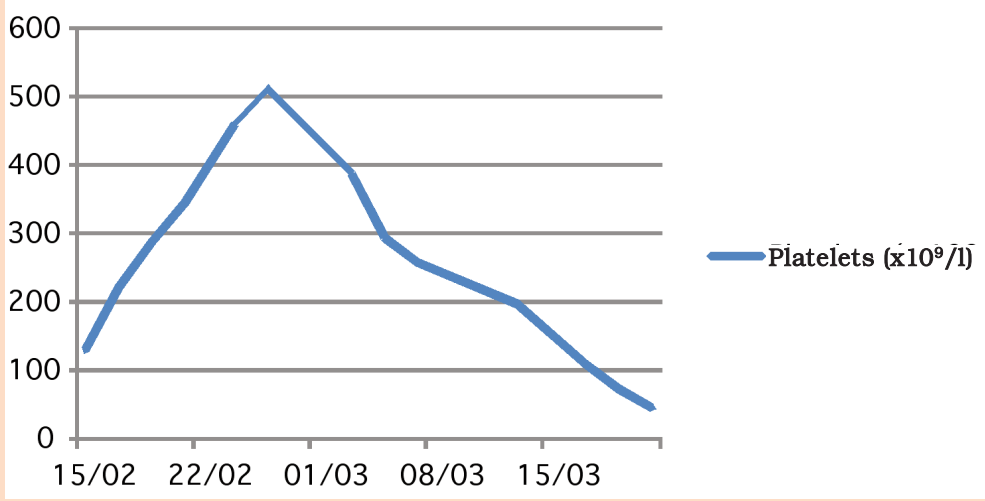

Fig. 6. Dynamics of platelet count with the exclusion of HIT Abbreviations: HIT - heparin-induced thrombocytopenia

No published results of randomized controlled trial studies have specifically addressed the issue of VTE treatment in acute leukaemia. A therapeutic strategy based on LMWH administered for 6 months after VTE episode has proved safe and superior to warfarin in preventing VTE recurrence (15).

Rivaroxaban is a promising alternative to traditional anticoagulants approved for prevention of stroke and systemic embolism in adult patients with non-valvular atrial fibrillation with one or more risk factors, as well as treatment of DVT and prevention of recurrent DVT and PE following an acute DVT in adults. It is an oral direct, reversible, competitive, rapid, and dose-dependent inhibitor of FXa $(9,10)$. Mechanism of action of rivaroxaban with FXa as its primary target is outlined in Figure 7.

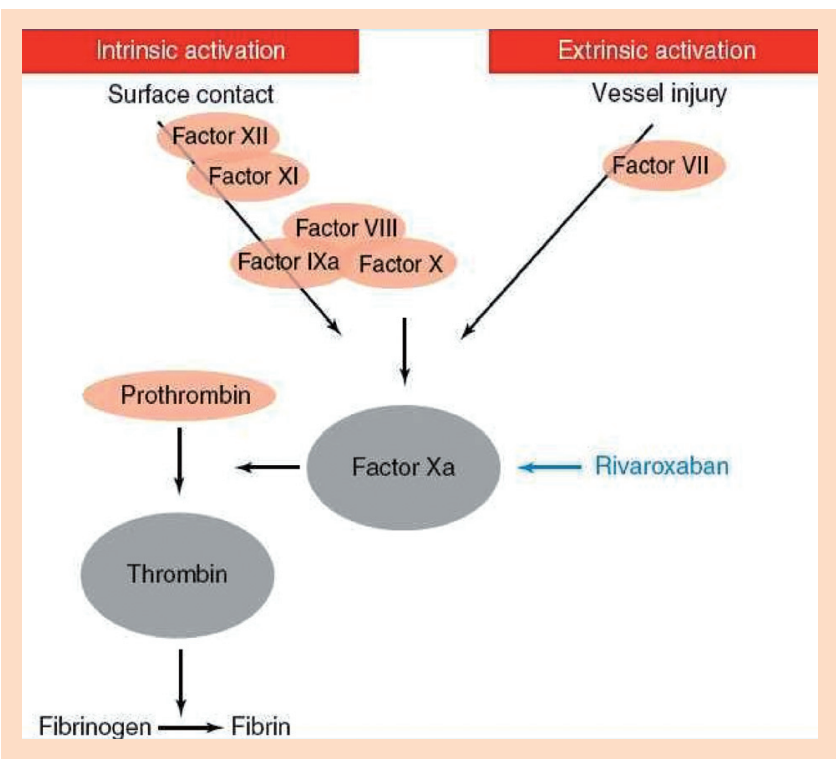

Fig. 7. Mechanism of action of rivaroxaban (adapted from: Parekh PJ, Merrell J, Clary M, Brush JE, Johnson DA. New Anticoagulants and Antiplatelet Agents. Am J Gastroenterol 2014; 109 (1): 919. DOI: 10.1038/ajg.2013.228) (16) 
FXa catalyzes the reaction that converts factor II (prothrombin) to factor IIa (thrombin). Because FXa acts at the convergence of the contact activation (intrinsic) and tissue factor (extrinsic) pathways, inhibition of FXa activity by rivaroxaban inhibits thrombin generation via both pathways. It offers the advantages of a fixed oral dose, rapid onset of action, and predictable and consistent anticoagulation effect, precluding the need for routine monitoring of anticoagulation $(9,10)$.

\section{CONCLUSION}

Our case report describes a case of a patient with DVT and leukaemic transformation of MDS to AML as relatively late first clinical manifestation of homozygous FV Leiden mutation. Diagnosis of DVT can be established on the basis of clinical signs, duplex ultrasonography as the method of choice and according to the level of D-dimers. Other diagnostic methods include computed tomography (CT), venography and spiral CT scans, isotope venography or magnetic resonance imaging $(13,17,18)$. In our case, the diagnosis of DVT was confirmed by ultrasound examination of the deep venous system of the LL and increased level of D-dimers. Treatment with new oral anticoagulant - rivaroxaban, administration of vasoprotective and moderately acting antithrombotic drugs (Detralex ${ }^{\circledR}$ and Vessel Due $F^{\circledR}$ ) in the combination with mechanical methods of VTE prophylaxis (compression bandages, limb positioning, sufficient exercise regimen) led to further alleviation of the symptoms of DVT of LL. Major questions remain regarding the optimalization of initial treatment in order to minimize long-term consequences. In the case of unsuccessful treatment complete DVT of LL leads to severe and chronic complications, such as post-thrombotic syndrome. Therefore, it is necessary to pay particular attention to the prophylaxis and treatment of DVT (13).

\section{LIST OF ABBREVIATIONS}

AML

APC

APTT

AT III

CT

DNA analysis

DVT

FV Leiden

FXa

HIT

LL

LMWH

MDS

MDS-RAEB-2

MTHFR

PAD

PCD

$\mathrm{PE}$

RL

UFH

VTE acute myeloid leukaemia

activated protein $\mathrm{C}$

activated partial thromboplastin time

antithrombin III

computed tomography

analysis of deoxyribonucleic acid

deep venous thrombosis

factor V Leiden

activated factor Xa

heparin-induced thrombocytopenia

left leg

low molecular weight heparin

myelodysplastic syndrome

myelodysplastic syndrome-refractory anaemia with excess blasts type 2

5,10-methylenetetrahydrofolate reductase

phlegmasia alba dolens

phlegmasia cerulea dolens

pulmonary embolism

right leg

unfractionated heparin

venous thromboembolism 


\section{REFERENCES}

1. Štvrtinová V, Labaš P. Venózny trombomembolizmus - definícia, princípy a metódy prevencie. In: Štvrtinová V, editor. Venózny tromboembolizmus: prevencia, diagnostika, liečba. 2.revised ed. Bratislava: Herba; 2009. p. $15-26$.

2. Kujovich JL. Factor V Leiden thrombophilia. Genet Med 2011; 13: 1-16. DOI: 10.1097/GIM.0b013e3181faa0f2

3. Arsov T, Miladinova D, Spiroski M. Factor V Leiden Is Associated with Higher Risk of Deep Venous Thrombosis of Large Blood Vessels. Croat Med J 2006; 47 (3): 433-439.

4. Deitcher SR, Rodgers GM. Thrombosis and Antithrombotic Therapy. In: Pine JW, Jr., editor. Wintrobe's clinical hematology. 12th ed. Philadelphia: Lippincott Williams \& Wilkins; 2009. p. 1464-1508.

5. Zaher GF, Abdelaal MA. Venous Thromboembolism in Cancer Patients. In: Abdelaal MA, editor. Pathophysiology and Clinical Aspects of Venous Thromboembolism in Neonates, Renal Disease and Cancer Patients. 1st ed. Rijeka: InTech; 2012. p. 73-114.

6. Kwaan HC. Double Hazard of Thrombophilia and Bleeding in Leukemia. ASH Education Book 2007; 2007 (1): 151-157. DOI: 10.1182/asheducation-2007.1.151

7. Hofírek I. Angiologie. In: Souček M, editor. Vnitřní lékařství: 1. díl. 1. ed. Praha - Brno: Praha Grada Publishing - Brno Facta Medica - Brno Muni Press; 2011. p. 174-182.

8. Hasegawa S, Aoyama T, Kakinoki R, Toguchida J, Nakamura T. Bilateral phlegmasia dolens associated with Trousseau's syndrome: a case report. Arch Phys Med Rehabil 2008; 89 (6): 1187-90. DOI: 10.1016/j.apmr.2007.10.030.

9. Gulseth MP, Michaud J, Nutescu EA. Rivaroxaban: An oral direct inhibitor of factor Xa. Am J Health-Syst Pharm 2008; 65: 1520-9. DOI: 10.2146/ajhp070624

10. Xarelto. [cit. 2014-07-01]. Access at webpage: <http://www.adcc.sk/web/humanne-lieky/spc/xarelto-spc50321.html>

11. Cushman M. Epidemiology and Risk Factors for Venous Thrombosis. Semin Hematol 2007; 44 (2): 62-69.

12. Kubisz P, Staško J. Tromboembolická choroba, trombofilné stavy. In:Kubisz P, Staško J, editors. Hematológia a transfuziológia. 1. ed. Bratislava - Praha: Grada Slovakia - Grada, Publishing; 2006. p. 193-216.

13. Schulman S, Marder VJ, White II, GC. Overview of Venous Thromboembolism. In: Marder VJ. editor. Hemostasis and Thrombosis: Basic Principles and Clinical Practice. 6th ed. Philadelphia: Wolters Kluwer, Lippincott Williams \& Wilkins; 2013. p. 957-961.

14. Marciniak E, Gockerman JP. Heparin-induced decrease in circulating antithrombin-III. Lancet 1977; 2 (8038): 581-4.

15. Oehadian A, Iqbal M, Sumantri R. Deep Vein Thrombosis in acute myelogenous leukemia. Acta Med IndonesIndo J Intern Med 2009; 41 (4): 200-4.

16. Parekh PJ, Merrell J, Clary M, Brush JE, Johnson DA. New Anticoagulants and Antiplatelet Agents. Am J Gastroenterol 2014; 109 (1): 9-19. DOI: 10.1038/ajg.2013.228.

17. Bates SM, Jaeschke R, Stevens SM, Goodacre S, Wells PS, Stevenson MD, Kearon C, Schunemann HJ, Crowther M, Pauker SG, Makdissi R, Guyatt GH. Diagnosis of DVT: Antithrombotic Therapy and Prevention of Thrombosis, 9th ed: American College of Chest Physicians Evidence-Based Clinical Practice Guidelines. Chest 2012; 141: e351S-e418S. DOI: 10.1378/chest.11-2299

18. Karetová D. Choroby žil. In: Klener P, editor. Vnitřní lékařství. 4th revised and supplemented ed. Prague: Galen, Karolinum; 2011. p. 351-361.

\section{Acknowledgement}

This work was supported by projects CEPV I (ITMS 26220120016), CEVYPET (ITMS 26220120053), APVV 0222-11 and Vega 1/0016/12.

Received: July,10,2014

Accepted: August,28,2014 